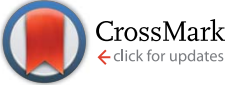

Cite this: RSC Adv., 2017, 7, 5980
Received 30th November 2016 Accepted 9th January 2017

DOI: 10.1039/c6ra27562a

www.rsc.org/advances

\section{A novel, low surface charge density, anionically modified montmorillonite for polymer nanocomposites $\uparrow$}

\author{
Deqi Yi, ${ }^{\text {a }}$ Huixin Yang, ${ }^{a}$ Min Zhao, ${ }^{a}$ Le Huang, ${ }^{a}$ Giovanni Camino, ${ }^{b}$ Alberto Frache ${ }^{b}$ \\ and Rongjie Yang ${ }^{a}$
}

A new, low surface charge density, anionically modified montmorillonite (MMT) has been prepared and its polyurethane nanocomposites are prepared. Their morphologies were studied using XRD, FTIR, SEM and EDS analysis, thermal stability by thermo-gravimetric analysis (TGA) and fire retardancy by cone calorimetry (CONE). Low surface charge density MMT forms due to conversion of $\left[\mathrm{MgO}_{6}\right]^{-}$to $\left[\mathrm{MgO}_{5} \mathrm{OH}\right]$ and $\left[\mathrm{AlO}_{4}\right]^{-}$to $\left[\mathrm{AlO} \mathrm{O}_{3} \mathrm{OH}\right]$ during the acidic treatment of $\mathrm{MMT}$ layers. Its anionic modification is related with $\mathrm{p} K_{\mathrm{a}}$ of modifier and $\mathrm{pH}$ of water solution by using Henderson-Hasselbalch equation. The low surface charge density MMT gives exfoliated nano-dispersion in PU, indicating that the dispersion of the MMT layers is not only decided by the organophilic surface, but also enhanced with a low surface charge density and electrostatic interaction between layers and counter ions. Low surface charge density MMT can enhance thermal stability and flame retardancy of PU with a small amount of anionic modifier, due to exfoliated nano-dispersion, and catalytic dehydrogenation and char formation. The large reduction in the THR for the sodium stearate modified low surface charge density MMT, SST-t-MMT, means that this material could be a solution for both fire risk and fire hazard.

\section{Introduction}

The utilization of various nano-dimensional materials to produce polymer nanocomposites is by now a well-known practice. ${ }^{\mathbf{1}}$ The materials that are most commonly used to form these nanocomposites are the various layered smectites; montmorillonite (MMT) has been especially widely used and investigated. $^{2-6}$ These polymer/clay nanocomposites (PCNs) offer enhanced mechanical, flame retardant, gas barrier and polymer recycling properties, ${ }^{7}$ which are all quite dependent on the dispersion. If the clay is not dispersed at the nanometer level, the enhanced properties are not displayed. ${ }^{8,9}$ The importance of dispersion has also been shown for a large number of other nano-dimensional materials, including layered double hydroxides $(\mathrm{LDH}),{ }^{10,11}$ carbon nanotubes, ${ }^{12,13}$ and various metal oxides, ${ }^{\mathbf{1 4 , 1 5}}$ phosphates, ${ }^{\mathbf{6}}$ sulfides, ${ }^{\mathbf{1 6}}$ etc. Simply stated, the attainment of enhanced polymer properties through the formation of a PCN requires good dispersion at the nanometer

${ }^{a}$ National Engineering Research Center of Flame Retardant Materials, School of Materials Science and Engineering, Beijing Institute of Technology, No. 5 South Zhongguancun Street, Haidian District, Beijing, 10081, China. E-mail: yidq@bit. edu.cn; Fax: +86-010-68913066; Tel: +86-010-68913066

${ }^{b}$ Polytechnic of Turin, Alessandria Campus, UdR INSTM of Turin, V.le Teresa Michel 5, 15121 Alessandria, Italy

$\dagger$ Electronic supplementary information (ESI) available: Original SEM images and EDS data. See DOI: 10.1039/c6ra27562a level. It can be rather difficult to disperse the quite polar (organophobic) clay in an organophilic polymer. Only a few polymers can be used with natural clay to prepare nanocomposites, such as poly(vinyl alcohol). ${ }^{17}$ For most polymers, the usual strategy is to organically modify the clay with an organic "onium" salt using cation exchange or organic molecules, using absorption to make it more organophilic. ${ }^{18,19} \mathrm{~A}$ few studies suggested that MMT can be modified by anions in the presence of some kinds of metal ions $\left(\mathrm{Ca}^{2+}, \mathrm{La}^{3+} \text {, etc. }\right)^{\mathbf{2 0 , 2 1}}$ or cationic modifiers due to electrostatic ion pairs attraction. ${ }^{22}$ But NaMMT cannot be intercalated by anions alone. ${ }^{23}$ Even then, industrial applications are difficult due to the limited dispersion that one may obtain by melt blending. ${ }^{24}$

Research on this topic has followed several paths, which can be simplified into two: finding new approaches and developing new methods to increase the dispersion of clay in the polymer. For new approaches, one which has developed in recent years is to coat the clay layers on the surface of the polymers using the layer-by-layer (LbL) self-assembly method, which has also been shown to improve fire retardancy; ${ }^{25}$ the other process is to incorporate the clay into the fire retardants. In previous work, ammonium polyphosphate/montmorillonite (APP/MMT) nanocompounds have been prepared where the MMT layers are exfoliated in ammonium polyphosphate, an important inorganic flame retardant. The APP/MMT nanocompounds combined with a char precursor and a gas source exhibit significantly enhanced fire retardancy in polypropylene 
(intumescent flame retardancy). ${ }^{26}$ But the mechanical properties enhancement vanished. Thus, the challenge to solve the dispersion of clay in the polymers still remains.

The clay organic modification has solved the interfacial compatibility between clay and polymer. But the electrostatic interaction between charged clay layers in presence of counter ions in the gallery may be a factor that affects the dispersibility of clay. Thus it is necessary to investigate the relationship between dispersion and the surface charge density of clay.

In this work, a novel, low surface charge density, anionically modified MMT is prepared, which gives exfoliated nanodispersion and enhanced fire retardancy in polyurethane. The dispersion of the MMT layers is not only determined by the organophilic surface, but also enhanced by a low surface charge density and electrostatic interaction between layers and counter ions.

\section{Experimental section}

\subsection{Materials}

NaMMT $($ CEC $\approx 100 \pm 10 \mathrm{mmol} / 100 \mathrm{~g}$ ) was purchased from Nanocor Inc. Sodium stearate (analytical reagent) and sodium dodecyl sulfonate (analytical reagent) were purchased from Tianjin Fuchen Chemical Reagents Factory. Hydrochloric acid $\left(1 \mathrm{~mol} \mathrm{~L}^{-1}\right)$ was purchased from Sinopharm Chemical Reagent Beijing Co., Ltd. Ammonium polyphosphate, form II, was from BIT flame retardance Co., Ltd. Polyurethane (PU) water emulsion (DISPERCOLL U54, solid content $50 \pm 1 \%$ ) was purchased from Bayer Inc.

\subsection{Preparation of low surface charge density, anionically modified MMT}

NaMMT $(2 \mathrm{~g})$ and $150 \mathrm{~mL}$ DI-water were placed in a round bottom three neck flask $(250 \mathrm{~mL})$ with vigorous magnetic stirring for $10 \mathrm{~min}$, and the $\mathrm{pH}$ of the suspension was adjusted to $1 \mathrm{using}$ hydrochloric acid. When the $\mathrm{pH}$ had stabilized, the suspension was heated to $80^{\circ} \mathrm{C}$ for $3 \mathrm{~h}$ with vigorous magnetic stirring under reflux to prepare treated MMT (t-MMT). Then, sodium stearate or sodium dodecyl sulfonate (1.2 CEC of NaMMT) was added and stirred for $1 \mathrm{~h}$ to prepare sodium stearate-MMT (SST-t-MMT) and sodium dodecyl sulfonate-MMT (SDS-t-MMT). The final products were centrifuged and washed using DI-water until the $\mathrm{pH}$ of the supernatant solution was about 7 . The materials were then dried in a vacuum oven at $100{ }^{\circ} \mathrm{C}$ for $24 \mathrm{~h}$.

\subsection{Preparation of PU composites}

PU water emulsion and SST-t-MMT or SDS-t-MMT was blended with a ball mill at room temperature for $2 \mathrm{~h}$ to prepare PU/SST-tMMT and PU/SDS-t-MMT composites. Then APP was added to the mill and blended for another $1 \mathrm{~h}$ to prepare PU/clay/APP samples. PU water emulsion and APP were blended with a ball mill at room temperature for $1 \mathrm{~h}$ to prepare PU/APP. The detailed compositions are listed in Table 1.

\subsection{Characterization}

Powder X-ray diffraction data were collected on an X'Pert PRO MPD diffractometer with $\mathrm{Cu}\left(\mathrm{K}_{\alpha}\right)$ source, $\lambda=1.54078 \AA$ with
Table 1 Formulations of PU composites

\begin{tabular}{lllll}
\hline Samples & $\begin{array}{l}\text { U54 } \\
\text { (solid content, \%) }\end{array}$ & $\begin{array}{l}\text { APP } \\
(\%)\end{array}$ & $\begin{array}{l}\text { SDS-t-MMT } \\
(\%)\end{array}$ & $\begin{array}{l}\text { SST-t-MMT } \\
(\%)\end{array}$ \\
\hline PU & 100 & - & - & - \\
PU/SDS-t-MMT & 95 & - & 5 & - \\
PU/SST-t-MMT & 95 & - & - & 5 \\
PU/APP & 90 & 10 & - & - \\
PU/SDS-t-MMT/APP & 85 & 10 & 5 & - \\
PU/SST-t-MMT/APP & 85 & 10 & - & 5
\end{tabular}

a step size of $0.033^{\circ}$ and scanning rate of $20 \mathrm{~s}$ per step. The morphologies and EDS were examined with Hitachi ultra-high resolution $\$ 4800$ field emission scanning electron microscope (FE-SEM). Transmission electron microscope (TEM) image was obtained using JEM-2100, after cryogenic microtoming using a Leica EM FC7. Fourier transform infrared (FTIR) spectra were obtained on a Nicolet 6700 spectrometer using the attenuated total reflectance method. Thermogravimetric analysis (TGA) was performed on a Netzsch F209 instrument under a nitrogen flow $20 \mathrm{~cm}^{3} \mathrm{~min}^{-1}$ at a heating rate of $10^{\circ} \mathrm{C} \mathrm{min}^{-1}$ from 40 to $900{ }^{\circ} \mathrm{C}$. Cone calorimeter experiments were performed on a Stanton Redcroft (FTT) instrument according to ASTM E 135410 , on $3 \mathrm{~mm}$ thick $100 \times 100 \mathrm{~mm}^{2}$ plaques at a heat flux of 50 $\mathrm{kW} \mathrm{m}{ }^{-2}$.

\section{Results and discussion}

\subsection{Morphologies}

The XRD traces of NaMMT, t-MMT, SDS-t-MMT and SST-tMMT are shown in Fig. 1 . The basal space $\left(d_{001}\right)$ of t-MMT shifts from $0.98 \mathrm{~nm}$ in pristine NaMMT to $1.03 \mathrm{~nm}$. Surprisingly, the t-MMT layers show homogeneously distributed holes (Fig. 2a, and S1 $†$ ). For the EDS, since a unit cell contains eight atoms of silicon, $\sim 3$ atoms of $\mathrm{Mg}$ and $\sim 0.5$ atoms of $\mathrm{Al}$, the data have all been

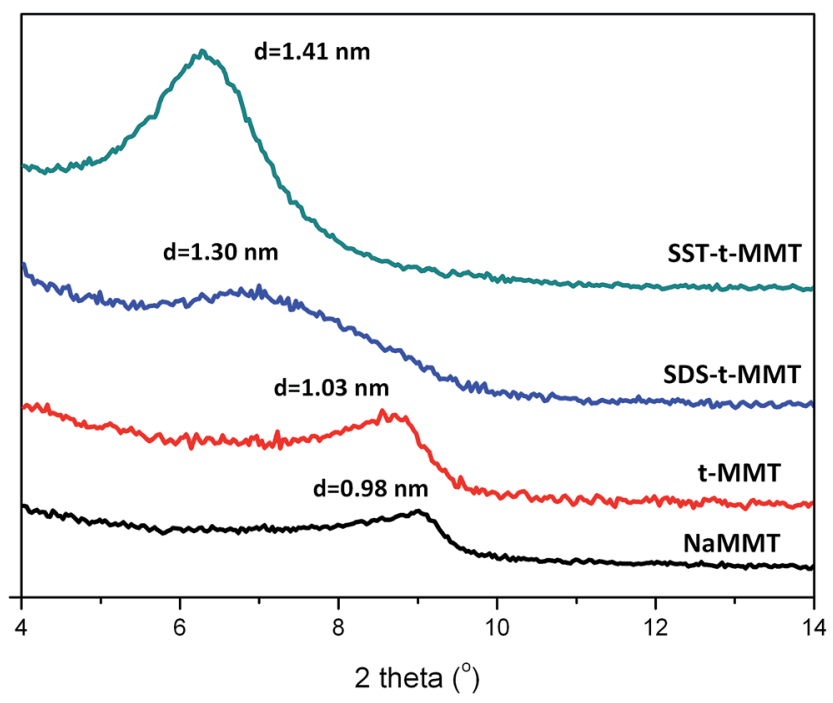

Fig. 1 XRD traces of NaMMT, SDS-t-MMT and SST-t-MMT. 

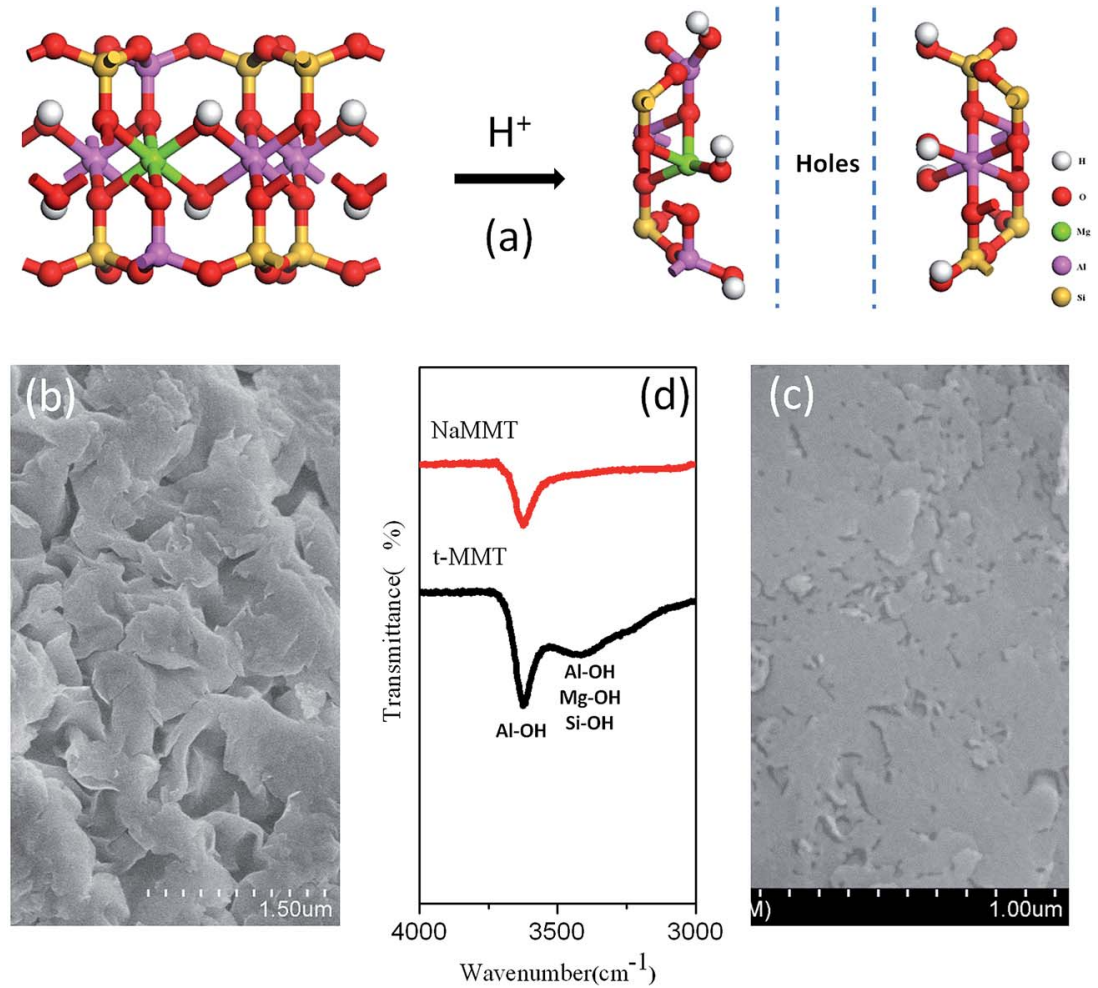

Fig. 2 Scheme of acidic treatment of MMT (a), SEM image of NaMMT (b) and t-MMT (c), and their FT-IR spectra (d).

transformed based on this number. The EDS data, shown in Table 2 (Fig. S2 and Table S1†), indicate that the t-MMT has low surface charge density due to the low sodium content, which is $\sim 1 / 10$ of NaMMT. In the infrared spectra, compared with NaMMT, the t-MMT has an increased peak at $3623 \mathrm{~cm}^{-1}$ for Al$\mathrm{OH}$ (octahedral sheet) and a new broad peak at $3388 \mathrm{~cm}^{-1}$ for $\mathrm{Al}-\mathrm{OH}, \mathrm{Mg}-\mathrm{OH}$ and $\mathrm{Si}-\mathrm{OH}$ (tetrahedral sheet and edge) (Fig. 2d), which correspond to the conversion of $\left[\mathrm{MgO}_{6}\right]^{-}$to $\left[\mathrm{MgO}_{5} \mathrm{OH}\right]$ and $\left[\mathrm{AlO}_{4}\right]^{-}$to $\left[\mathrm{AlO}_{3} \mathrm{OH}\right]$ during the acidic treatment of MMT layers (Fig. 2a). The results indicate that there are defects of $\left[\mathrm{SiO}_{4}\right] \rightarrow\left[\mathrm{AlO}_{4}\right]^{-}$in the tetrahedral sheet and $\left[\mathrm{AlO}_{6}\right]$ $\rightarrow\left[\mathrm{MgO}_{6}\right]^{-}$in the octahedral sheet, ${ }^{27,28}$ which produce negative charges that are counterbalanced by sodium ions in the gallery space. The defects can accumulate and lead to the formation of holes on the MMT layers using acid with a specific $\mathrm{pH}$, while the surface charge density of MMT is reduced.

The $d$-space of SST-t-MMT and SDS-t-MMT are $1.41 \mathrm{~nm}$ and $1.30 \mathrm{~nm}$, respectively, indicating that the modifiers are intercalated into the MMT gallery. Compared with SST-t-MMT, the

Table 2 Elemental composition of Na-MMT, t-MMT, SSS-t-MMT and SDS-t-MMT in a cell unit, from EDS analysis

\begin{tabular}{lllll}
\hline Elements & Na-MMT & t-MMT & SDS-t-MMT & SST-t-MMT \\
\hline $\mathrm{Na}$ & 0.672 & 0.046 & 1.104 & 0.184 \\
$\mathrm{~S}$ & - & - & 1.094 & - \\
$\mathrm{Mg}$ & 0.446 & 0.427 & 0.504 & 0.528 \\
$\mathrm{Al}$ & 2.974 & 3.002 & 3.192 & 2.896 \\
$\mathrm{Si}$ & 8 & 8 & 8 & 8
\end{tabular}

001 reflection of the SDS-t-MMT is significantly broadened (full width at half maximum (FWHM)) indicating efficient splitting of platelets into thinner tactoids, and that the SDS is not homogenously distributed in the galleries.

The sodium content is 0.181 for SST-t-MMT and 1.104 for SDS-t-MMT (Table 2). One can use simple equilibrium notions (Henderson-Hasselbalch equation) to show that at $\mathrm{pH}=1$, stearic acid is the dominate form while for dodecyl sulfate, the anion is dominant. Thus there are very few anions with strearate and hence a low sodium content while the sodium dodecylsulfate is prevalent in SDS. The sulfur content of the SDS-t-MMT is 1.094, which is relatively proximate to that of sodium, indicating one sodium per anion. At a specific $\mathrm{pH}$, the molar ratio of the undissociated week acid [HA] and its conjugate base $\left[\mathrm{A}^{-}\right]$can be calculated according to the HendersonHasselbalch equation (eqn (1)). ${ }^{29}$ The $\mathrm{p} K_{\mathrm{a}}$ of stearic acid (STA) and dodecyl sulphonic acid (DSA) are 4.95 and -0.59 , respectively. When the $\mathrm{pH}=1$, the molar ratio of [stearic acid] and [stearic anion] is about 9000, and the molar ratio of [dodecyl sulfuric acid] and [dodecyl sulfuric anion] is about $1 / 40$, which fit with the EDS results.

$$
\mathrm{p} K_{\mathrm{a}}=\mathrm{pH}+\lg \left([\mathrm{HA}] /\left[\mathrm{A}^{-}\right]\right)
$$

Fig. 3 gives the thermogravimetric analysis (TGA) curves of the MMT samples. NaMMT shows a thermal degradation stage at $\sim 600{ }^{\circ} \mathrm{C}$ due to the dehydration of the $-\mathrm{OH}$ group bridged on $\mathrm{Al}-\mathrm{O}-\mathrm{Al}$ bonds in the $\left[\mathrm{AlO}_{6}\right]$ octahedral sheet, which can be found in all of the MMT samples. The t-MMT has a mass loss of $1.5 \%$ before $500{ }^{\circ} \mathrm{C}$, which corresponds to the $-\mathrm{OH}$ group at the 


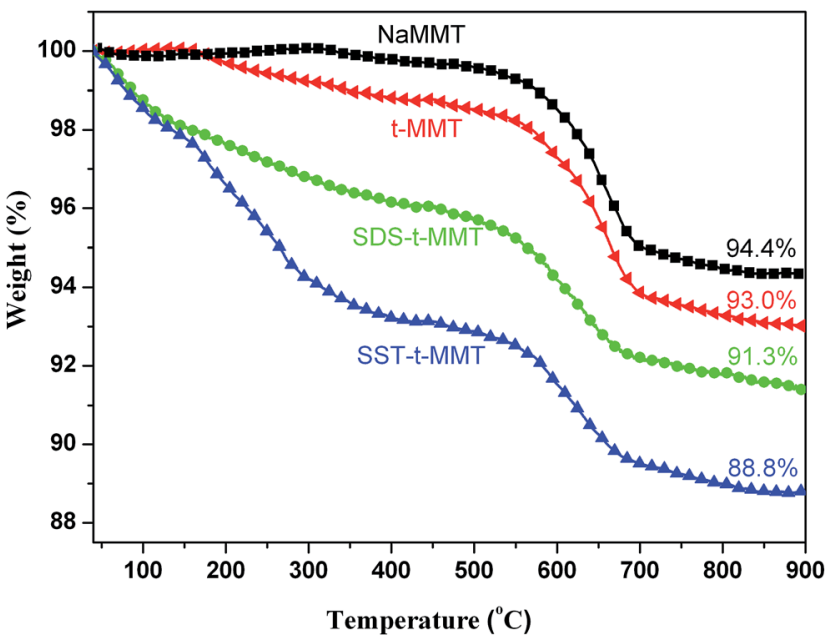

Fig. 3 TGA curves of NaMMT, t-MMT, SDS-t-MMT and SST-t-MMT.

MMT surface. Due to the organic modification, there is a larger mass loss in both SDS-t-MMT and SST-t-MMT. The residues of NaMMT, t-MMT, SDS-t-MMT and SST-t-MMT are 94.4\%, 93.0\%, $91.3 \%$ and $88.8 \%$, respectively. The organic modifier content can be calculated using the differences between organically modified MMT and t-MMT, 1.7\% for SDS-t-MMT and $4.2 \%$ for SST-t-MMT, which supports the difference in the basal spacing.

As shown in Fig. 4, the modification procedure can be described as follows:

(1) The MMT layers are made of two silica tetrahedrons fused to an edge-shared octahedral sheet of alumina. There are defects of $\left[\mathrm{SiO}_{4}\right]-\left[\mathrm{AlO}_{4}\right]^{-}$in the tetrahedral sheet and $\left[\mathrm{AlO}_{6}\right]-$ $\left[\mathrm{MgO}_{6}\right]^{-}$in the octahedral sheet, ${ }^{27,28}$ which produce negative charges that are counterbalanced by sodium ions in the gallery.
The defects can combine and produce holes on the MMT layers because of the conversion of $\left[\mathrm{MgO}_{6}\right]^{-}$to $\left[\mathrm{MgO}_{5} \mathrm{OH}\right]$ and $\left[\mathrm{AlO}_{4}\right]^{-}$ to $\left[\mathrm{AlO}_{3} \mathrm{OH}\right]$ on acid treatment which leads to a reduced surface charge density.

(2) According to the $\mathrm{p} K_{\mathrm{a}}$ of stearic acid (STA, 4.95) and dodecyl sulphonic acid (DSA, -0.59) by using HendersonHasselbalch equation, when $\mathrm{pH}$ of water solution is 1 , the organic acid salts dissolve in the acidic water and stearic acid, a weak acid, is primarily in the molecular form, while the dodecylsulfate is mostly in the form of the anion.

(3) In the water solution, the MMT swells. ${ }^{30}$ Thus the gallery space is significantly increased and oppositely charged pairs diffuse into the gallery.

(4) After filtration, the most molecules and oppositely charged pairs are washed out. A small amount of stearic acid or sodium dodecyl sulfonate ion pairs remain in the gallery due to the hydrogen bonds and low sodium content. The content of dodecylsulfate ion is lower because the sodium ion used to balance the charge of dodecyl sulfuric ion occupies a portion of the volume. Based on energy minimization, the chain of organic molecules should prefer a horizontal orientation relative to the MMT surface. ${ }^{31,32}$

\subsection{Morphologies of PU samples}

TEM images show the MMT is exfoliated in PU/SST-t-MMT (Fig. 5a), while in SDS-t-MMT crystallites of MMT with thickness of $\sim 200 \mathrm{~nm}$ are observed due to the poor organophilic surface modification (Fig. 5b). The dispersion of the layered clays is not only determined by the organophilic surface, but the surface charge density and electrostatic interaction between layers and counter ions are also involved. The novel, low surface charge density, anion modified MMT, SST-t-MMT, has good dispersibility in PU.

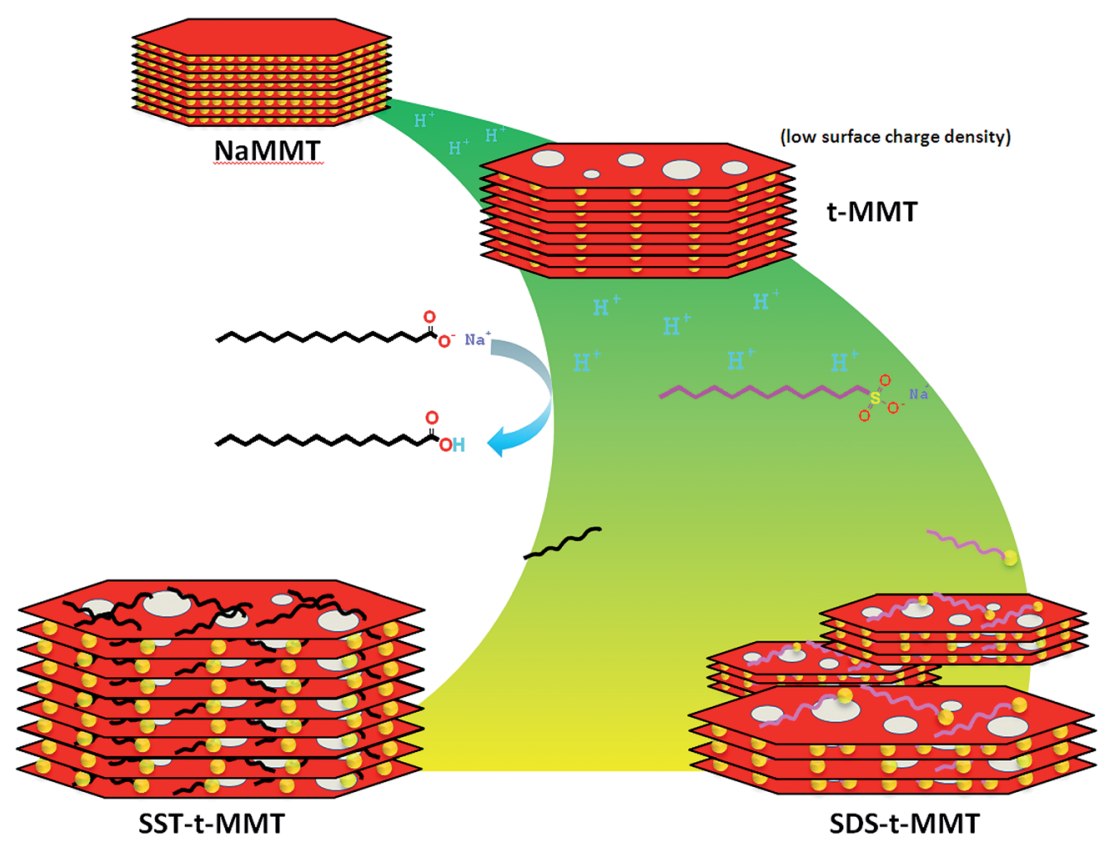

Fig. 4 Scheme of low charge density, anionically modified MMT process at $\mathrm{pH}=1$. 

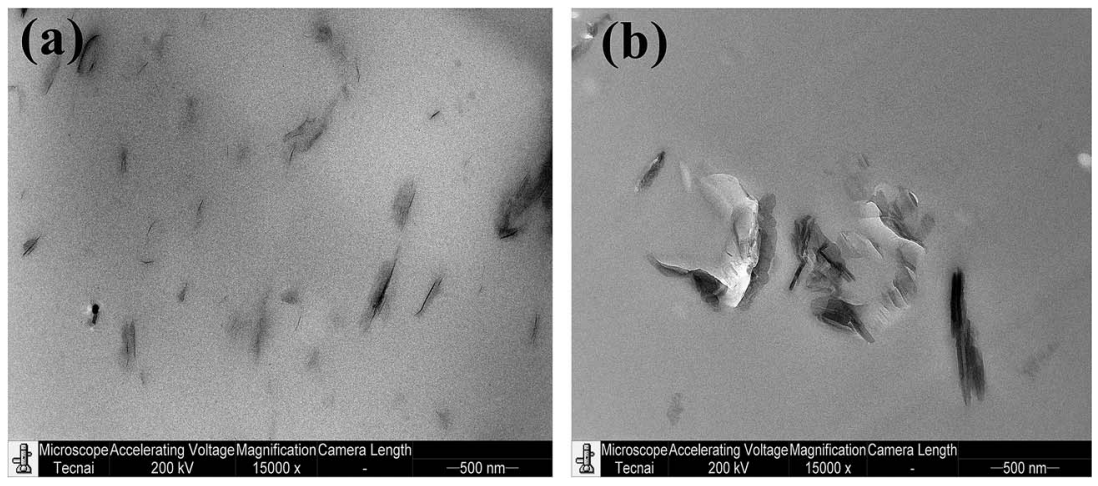

Fig. 5 TEM images of PU/SST-t-MMT (a) and PU/SDS-t-MMT (b).

\subsection{Thermal stability}

Fig. 6 gives the thermogravimetric analysis (TGA) curves of the PU samples. The mass loss at $1 \mathrm{wt} \%$ degradation, taken as the onset of the degradation $\left(T_{\text {onset }}\right)$, maximum mass loss rate temperature $\left(T_{\max }\right)$ obtained from the DTG curves and the fraction of the residue remaining at $600{ }^{\circ} \mathrm{C}$, char are listed in Table 3.

Compared with PU, the onset of the PU/SDS-t-MMT composite is decreased by $15{ }^{\circ} \mathrm{C}$ while the $T_{\max }$ is decreased about $17^{\circ} \mathrm{C}$. For the PU/SST-t-MMT nanocomposite, the onset is decreased about $5{ }^{\circ} \mathrm{C}$ while the $T_{\max }$ is increased about $5{ }^{\circ} \mathrm{C}$. Compared with the PU/SDS-t-MMT, the PU/SST-t-MMT has higher residue at $5.8 \%$. The results indicate that the thermal stability of nanocomposites is related to the dispersion level of clay.

For all APP samples, both $T_{\text {onset }}$ and $T_{\max }$ are decreased due to char formation between APP and PU. The residue of PU/SDSt-MMT is decreased from $11.6 \%$ in PU/APP to $7.8 \%$. The residue of SST-t-MMT is increased at $16.7 \%$. The results indicated that the char formation can be significantly different with the dispersion of clay and the chemical nature of organic modifiers.

\subsection{Cone calorimetric studies}

Cone calorimetry is one of the most effective bench-scale methods to study the flammability properties of materials. The main parameters obtained are: time to ignition (TTI); heat release rate (HRR), and especially its peak value (PHRR); total
Table 3 TGA data of PU composites

\begin{tabular}{lllc}
\hline Samples & $T_{\text {onset }} /{ }^{\circ} \mathrm{C}$ & $T_{\max } /{ }^{\circ} \mathrm{C}$ & Residue/\% \\
\hline PU & 321.0 & 404.1 & 1.6 \\
PU/SDS-t-MMT & 296.0 & 386.9 & 4.5 \\
PU/SST-t-MMT & 316.3 & 409.1 & 5.8 \\
PU/APP & 278.2 & 323.0 & 11.6 \\
PU/SDS-t-MMT/APP & 285.2 & 374.9 & 7.8 \\
PU/SST-t-MMT/APP & 285.3 & 346.7 & 16.7 \\
\hline
\end{tabular}

heat released (THR); total smoke release (TSR); mass loss rate (MLR) and char yield.

All of cone calorimetric data for PU, PU/SDS-t-MMT, PU/SSTt-MMT, PU/APP, PU/SDS-t-MMT/APP and PU/SST-t-MMT/APP are collected in Table 4 and the heat release rate (HRR) and mass loss rate (MLR) curves are shown in Fig. 7a and b, respectively. The addition of MMT only to PU has significant PHRR reduction $\left(R_{\mathrm{PHRR}}\right)$ by $23 \%$ for PU/SDS-t-MMT composite and $38 \%$ for PU/SST-t-MMT nanocomposite.

All APP samples show an even higher PHRR reduction due to char formation between APP and PU. The PU/SST-t-MMT/APP has the highest PHRR reduction of 79\%. A significant THR reduction of $45 \%$ and a large char yield of $28 \%$ are observed in the PU/SST-t-MMT/APP owing to extensive PU charring.

The char photographs of PU samples after cone calorimetry are shown in Fig. 8. Pure PU is completely burned and shows no char. PU/SDS-t-MMT composite shows little char. On the other
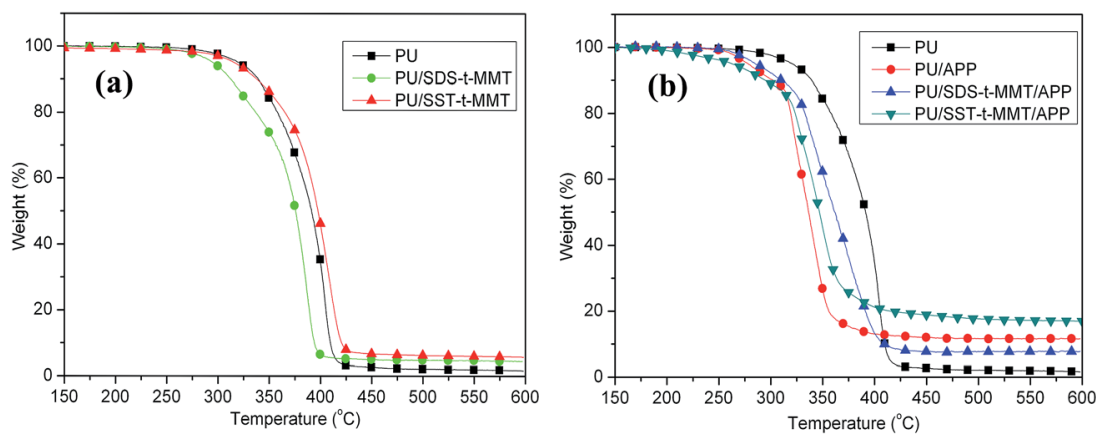

Fig. 6 TGA curves of PU composites. 
Table 4 Cone calorimetric data of PU composites

\begin{tabular}{llllll}
\hline Samples & $\begin{array}{l}\text { TTI } \\
(\mathrm{s})\end{array}$ & $\begin{array}{l}\text { PHRR } \\
\left(\mathrm{kW} \mathrm{m}^{-2}\right)\end{array}$ & $\begin{array}{l}R_{\text {PHRR }} \\
(\%)\end{array}$ & $\begin{array}{l}\text { THR } \\
\left(\mathrm{MJ} \mathrm{m}^{-2}\right)\end{array}$ & $\begin{array}{l}\text { Residue } \\
(\%)\end{array}$ \\
\hline Pure PU & 38 & 1033 & 0 & 89 & 0 \\
PU/SDS-t-MMT & 25 & 798 & $23 \%$ & 84 & 4 \\
PU/SST-t-MMT & 30 & 642 & $38 \%$ & 82 & 13 \\
PU/APP & 21 & 336 & $68 \%$ & 77 & 15 \\
PU/SDS-t-MMT/APP & 14 & 402 & $61 \%$ & 69 & 10 \\
PU/SST-t-MMT/APP & 13 & 218 & $79 \%$ & 49 & 28
\end{tabular}

hand, the PU/SST-t-MMT nanocomposite shows an intumescent char with remarkable char yield of $13 \%$ (5\% is MMT) because dehydrogenation of PU catalyzed by the acidic sites in t-MMT into unsaturated structures with aromatic rings, and the subsequent reactions increase char formation in the condensed phase. ${ }^{33}$ PU/APP shows an intumescent char with many cracks because PU partially plays the role of charring agent and reacts with APP to form the char. ${ }^{34}$ In contrast with PU/APP, PU/SDS-tMMT/APP and PU/SST-t-MMT/APP produce an intumescent char without cracks, indicating that the char formation procedure is modified with the addition of MMT.
Further char structure information of PU/APP and PU/SST-tMMT/APP were observed using SEM as shown in Fig. 9. The char of PU/APP can be clearly separated into surface and interior: the surface char contains many holes (Fig. 9a), which provide tunnels for flammable gas escape. While the interior char is a classic blown cellular intumescent char (Fig. 9b). PU/SST-tMMT/APP shows a kind of well-covered intumescent char, which can offer barrier properties and decrease flammability of PU (Fig. 9c and d). The char residue of PU/SST-t-MMT/APP is in good agreement with the sum of char yield of PU/SST-t-MMT and PU/APP.

The char structure has been characterized by ATR FTIR, as shown in Fig. 10. The char of PU/APP has spectra which is similar to graphite, meaning that a conjugated structure has been produced owing to char formation between PU and APP. ${ }^{35}$ The char of PU/SDS-t-MMT/APP shows a strong peak at about $1050 \mathrm{~cm}^{-1}$, which is attributed to Si-O stretching in MMT. ${ }^{36}$ The char of PU/SST-t-MMT shows a broad peak between 1200 and $940 \mathrm{~cm}^{-1}$, indicating that the layered structure of MMT is partly destroyed and a ceramic char is formed. ${ }^{35,36}$ It is also reported that the clay layers in polymer/clay nanocomposites migrate to surface and form ceramic char during combustion. ${ }^{33}$
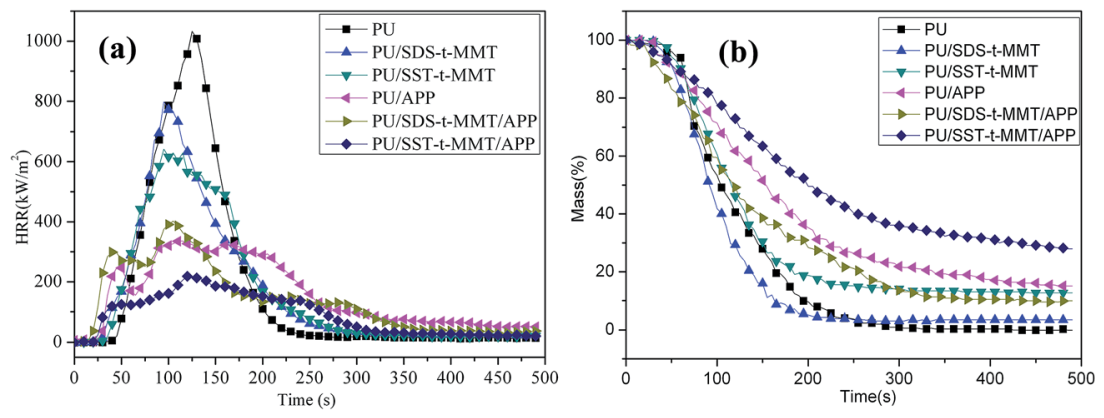

Fig. 7 HRR and mass loss rate curves of PU composites.

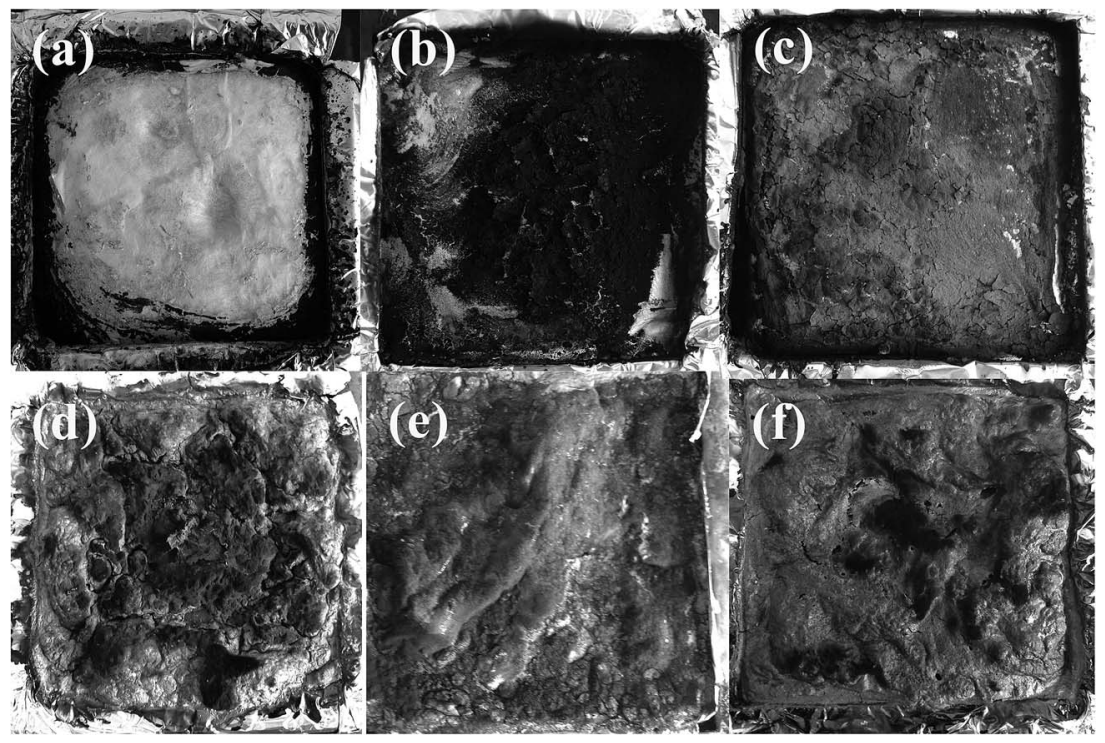

Fig. 8 Char residue images of PU (a), PU/SDS-t-MMT (b), PU/SST-t-MMT (c), PU/APP (d), PU/SDS-t-MMT/APP (e) and PU/SST-t-MMT (f). 

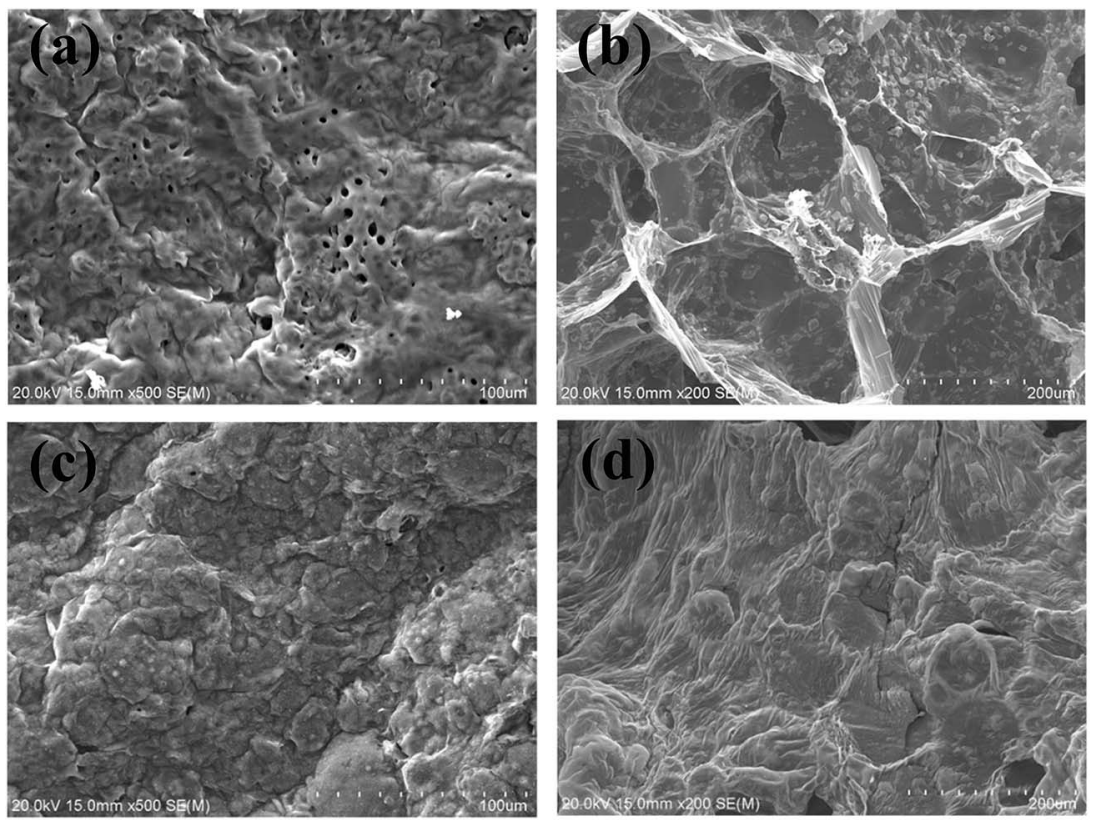

Fig. 9 SEM images of char residue of PU/APP (external (a) and internal (b)) and PU/SST-t-MMT/APP (external (c) and internal (d)).

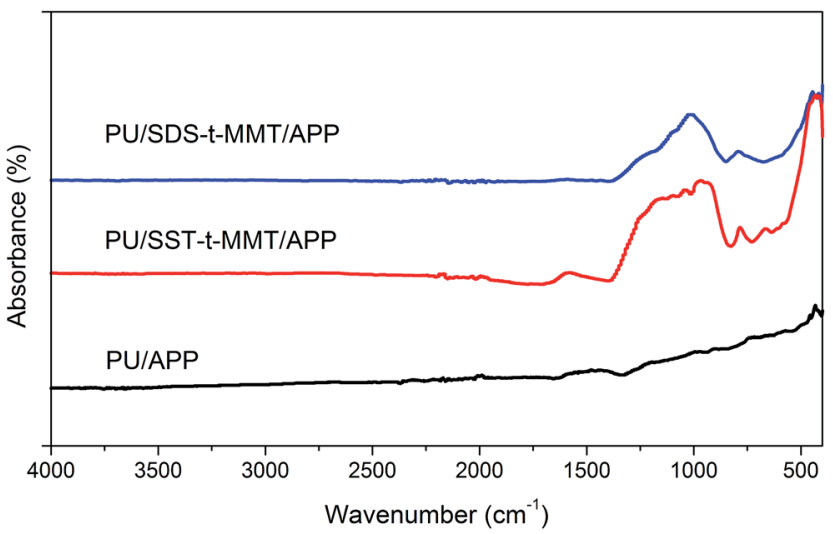

Fig. 10 FTIR spectra of the char of PU/APP, PU/SST-t-MMT/APP and PU/SDS-t-MMT/APP.

\subsection{Correlation studies}

Table 5 summarizes the correlation coefficients, $R$, for the TGA and cone parameters of PU composites, calculated by Microsoft Office Excel 2003.

For cone results, the parameters have high correlation by each other, except TTI with Re-cone, because the ignition occurs before the char formation. $T_{\text {onset }}$ has high correlation with TTI and PHRR owing to combustible gases arising from the thermal degradation of the sample. Then the ignition occurs when an ignitable blend of air and combustible gases. Re-TGA has high correlations with TTI, PHRR, THR and Re-cone, suggests that the fire retardant mechanism is mainly condensed phase.

\subsection{Char formation mechanism}

According to TGA, cone results and char structure, a possible char formation mechanism is draw in Fig. 11, in PU/SST-t-MMT/
Table 5 The correlation coefficients between TGA and cone data of PU composites

\begin{tabular}{|c|c|c|c|c|c|c|c|}
\hline & \multicolumn{3}{|l|}{ TGA } & \multicolumn{4}{|l|}{ Cone } \\
\hline & $T_{\text {onset }}$ & $T_{\max }$ & Re-TGA & TTI & PHRR & THR & Re-cone \\
\hline$T_{\text {onset }}$ & 1.000 & & & & & & \\
\hline$T_{\max }$ & 0.889 & 1.000 & & & & & \\
\hline Re-TGA & -0.747 & -0.809 & 1.000 & & & & \\
\hline TTI & 0.883 & 0.675 & -0.810 & 1.000 & & & \\
\hline PHRR & -0.830 & -0.787 & 0.930 & -0.900 & -1.000 & & \\
\hline THR & 0.623 & 0.571 & -0.906 & 0.846 & 0.839 & 1.000 & \\
\hline Re-cone & -0.554 & -0.621 & 0.956 & -0.716 & -0.880 & -0.895 & 1.000 \\
\hline
\end{tabular}

APP, APP is dispersed in PU with micro-size and MMT layers are nano-dispersed in PU, meaning that APP is covered with PU chains and only a few MMT layers are at the interface between APP and PU (step 1). There are two fast reactions occurring on heating: char formation between APP and PU to produce char layer; the nano-dispersed t-MMT layers containing acidic sites show catalytic dehydrogenation and char formation between MMT and PU to form ceramic char and move the surface. ${ }^{33}$ Thus the collision possibility between MMT and APP is very limited in the PU/SST-t-MMT/APP according to the collision theory (step $2) .{ }^{37}$ During the combustion, the ceramic char, carbonaceous silicate, modify the viscosity of the char layers to form intumescent char with controlled cell size. While the carbonaceous silicates mandate a tortuous pathway and pack the gas to hinder flammable gas diffusion (step 3). Finally, an intumescent char with ceramic char covered closed cell form as shown in Fig. 9c and $\mathrm{d}$, and the char yield of PU/SST-t-MMT/APP is equal to the sum of intumescent char from PU/APP and carbonaceoussilicate char from PU/SST-t-MMT (step 4), which slows down the rate of heat and mass transfer, and leads to the lower THR. 
(1)

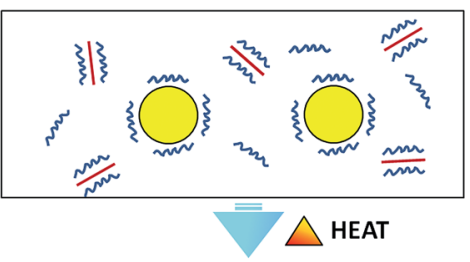

(2)

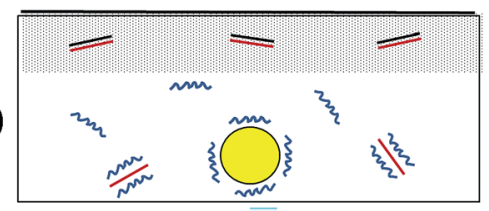

(3)

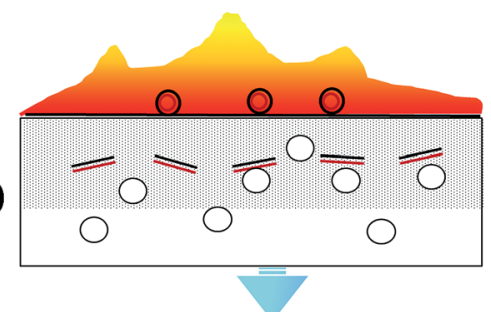

(4)
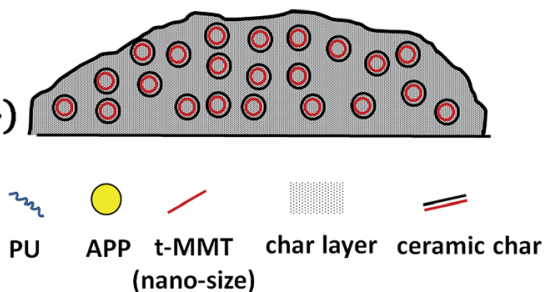

Fig. 11 Scheme of char formation mechanism of PU/SST-t-MMT/APP

\section{Conclusions}

A novel, low surface charge density, anionically modified MMT has been prepared. The defects of MMT layers can combine and produce holes on the MMT layers on acid treatment which leads to a reduced surface charge density. Its anionic modification is related with $\mathrm{p} K_{\mathrm{a}}$ of modifier and $\mathrm{pH}$ of water solution by using Henderson-Hasselbalch equation. The low surface charge density MMT gives exfoliated nano-dispersion in PU, indicating that the dispersion of the MMT layers is not only decided by the organophilic surface, but also enhanced with a low surface charge density and electrostatic interaction between layers and counter ions. Nano-dispersed low surface charge density MMT, t-MMT, contains more acidic sites and shows catalytic dehydrogenation and char formation in PU. When SST-t-MMT combined with APP in PU, a large reduction of PHRR and THR are observed, showing that this material could be a solution for both fire risk and fire hazard.

\section{Acknowledgements}

The work was partially financially supported by the National Natural Science Foundation of China under grant number 51303012, and the Nation High Technology Research and Development Program of China (863 Program) under grant number 2013AA032003, and the International Science \& Technology Cooperation Program of China under grant number 2014DFA52900.

\section{References}

1 D. D. Jiang, in Fire Retardancy of Polymeric Materials: Polymer Nanocomposites, ed. C. A. Wilkie and A. B. Morgan, CRC Press, Boca Raton, 2010, p. 262.

2 J. Zhu, A. B. Morgan, F. J. Lamelas and C. A. Wilkie, Fire properties of polystyrene-clay nanocomposites, Chem. Mater., 2001, 13, 3774-3780.

3 S. Su, D. D. Jiang and C. A. Wilkie, Polybutadiene-modified clay and its nanocomposites, Polym. Degrad. Stab., 2004, 84, 279-288.

4 M. C. Costache, M. J. Heidecker, E. Manias, G. Camino, A. Frache, G. Beyer, R. K. Gupta and C. A. Wilkie, The influence of carbon nanotubes, organically modified montmorillonites and layered double hydroxides on the thermal degradation and fire retardancy of polyethylene, ethylene-vinyl acetate copolymer and polystyrene, Polymer, 2007, 48, 6532-6545.

5 F. Leroux and J. P. Besse, Polymer interleaved layered double hydroxide: a new emerging class of nanocomposites, Chem. Mater., 2001, 13, 3507-3515.

6 H. J. Sue, K. T. Gam, N. Bestaoui, N. Spurr and A. Clearfield, Epoxy nanocomposites based on the synthetic $\alpha$-zirconium phosphate layer structure, Chem. Mater., 2004, 16, 242-249.

7 M. Si, T. Araki, H. Ade, A. L. D. Kilcoyne, R. Fisher, J. C. Sokolov and M. H. Rafailovich, Compatibilizing bulk polymer blends by using organoclays, Macromolecules, 2006, 39, 4793-4801.

8 P. Podsiadlo, A. K. Kaushik, E. M. Arruda, A. M. Waas, B. S. Shim, J. Xu, H. Nandivada, B. G. Pumplin, J. Lahann, A. Ramamoorthy and N. A. Kotov, Ultrastrong and stiff layered polymer nanocomposites, Science, 2007, 318, 80-83.

9 B. N. Jang, M. Costache and C. A. Wilkie, The relationship between thermal degradation behavior of polymer and the fire retardancy of polymer/clay nanocomposites, Polymer, 2005, 46, 10678-10687.

10 C. Nyambo, E. Kandare, D. Wang and C. A. Wilkie, Flameretarded polystyrene: investigating chemical interactions between ammonium polyphosphate and $\mathrm{MgAl}$ layered double hydroxide, Polym. Degrad. Stab., 2008, 93(9), 16561663.

11 A. llaik, C. Taviot-Guého, J. Lavis, S. Commereuc, V. Verney and F. Leroux, Unusual polystyrene nanocomposite structure using emulsifier-modified layered double hydroxide as nanofiller, Chem. Mater., 2008, 20, 4854-4860.

12 M. Moniruzzaman and K. I. Winey, Polymer nanocomposites containing carbon nanotubes, Macromolecules, 2006, 39, 5194-5205.

13 V. Datsyuk, C. Guerret-Piecourt, S. Dagreou, L. Billon, J.-C. Dupin, E. Flahaut, A. Peigney and C. Laurent, Double walled carbon nanotube/polymer composites via in situ nitroxide mediated polymerisation of amphiphilic block copolymers, Carbon, 2005, 43, 873-876. 
14 S. M. Khaled, R. Sui, P. A. Charpentier and A. S. Rizkalla, Synthesis of $\mathrm{TiO}_{2}$-PMMA nanocomposite: using methacrylic acid as a coupling agent, Langmuir, 2007, 23, 3988-3995.

15 Z. Guo, T. Pereira, O. Choi, Y. Wang and H. T. Hahn, Surface functionalized alumina nanoparticle filled polymeric nanocomposites with enhanced mechanical properties, $J$. Mater. Chem., 2006, 16, 2800-2808.

16 J. N. Coleman, M. Lotya, A. O'Neill, S. D. Bergin, P. J. King, V. Nicolosi, et al., Two-dimensional nanosheets produced by liquid exfoliation of layered materials, Science, 2011, 331, 568-571.

17 M. C. Corobea, D. Donescu, C. Petcu, C. Radovici, S. Serban, E. Constantinescu and M. Miculescu, Polyvinyl alcohol-Na montmorillonite nanocomposites films obtained by solution intercalation, J. Optoelectron. Adv. Mater., 2007, 9, 3358-3360.

18 Y. Kojima, A. Usuki, M. Kawasumi, A. Okada, Y. Fukushima, T. Kurauchi and O. Kamigaito, Mechanical properties of nylon 6-clay hybrid, J. Mater. Res., 1993, 8, 1185-1189.

19 G. B. Beall and M. Goss, Self-assembly of organic molecules on montmorillonite, Appl. Clay Sci., 2004, 27, 179-186.

20 Z. Zhang, L. Liao and Z. Xia, Ultrasound-assisted preparation and characterization of anionic surfactant modified montmorillonites, Appl. Clay Sci., 2010, 50, 576-581.

21 H. Wang, H. Wang, K. Chen, Y. Song, Z. Wei and M. Xue, The modification of lanthanum - exchanged montmorillonite with anionic surfactants to enhance the thermal stability of polyvinyl chloride, J. Appl. Polym. Sci., 2015, 132, 41535.

22 D. Chen, J. X. Zhu, P. Yuan, S. T. Yang, T. H. Chen and H. P. He, Preparation and characterization of anioncationic surfactants modified montmorillonite, J. Therm. Anal. Calorim., 2008, 94, 841-848.

23 P. Čapková, M. Pospíśil, M. Valášková, D. Měřínská, M. Trchová, Z. Sedláková, Z. Weiss and J. Šimoník, Structure of montmorillonite cointercalated with stearic acid and octadecylamine: modeling, diffraction, IR spectroscopy, J. Colloid Interface Sci., 2006, 300, 264-269.

24 P. Kiliaris and C. D. Papaspyrides, Polymer/layered silicate (clay) nanocomposites: an overview of flame retardancy, Prog. Polym. Sci., 2010, 35, 902-958.

25 F. Carosio, G. Laufer, J. Alongi, G. Camino and J. C. Grunlan, Layer by layer assembly of silica-based flame retardant thin film on PET fabric, Polym. Degrad. Stab., 2011, 96, 745-750.
26 D. Yi and R. Yang, Ammonium polyphosphate/ montmorillonite nanocompounds in polypropylene, $J$. Appl. Polym. Sci., 2010, 118, 834-840.

27 N. T. Skipper, F. C. Chang and G. Sposito, Monte Carlo simulation of interlayer molecular structure in swelling clay minerals. 1. Methodology, Clays Clay Miner., 1995, 43, 285-293.

28 R. T. Cygan, J. J. Liang and A. G. Kalinichev, Molecular models of hydroxide, oxyhydroxide and clay phases and the development of a general force field, J. Phys. Chem. B, 2004, 108, 1255-1266.

29 https://www.en.wikipedia.org/wiki/Henderson\%E2\%80\%93Hasselbalch_equation.

30 J. M. H. Emiel and S. Berend, Why clays swell, J. Phys. Chem. $B, 2002,106,12664-12667$.

31 H. Heinz, R. A. Vaia, R. Krishnamoorti and B. L. Farmer, Selfassembly of alkylammonium chains on montmorillonite: effect of chain length, head group structure, and cation exchange capacity, Chem. Mater., 2007, 19, 59-68.

32 D. Yi, R. Yang and C. A. Wilkie, Layered double hydroxidemontmorillonite - a new nano-dimensional material, Polym. Adv. Technol., 2013, 24, 204-209.

33 M. Zanetti, T. Kashiwagi, L. Falqui and G. Camino, Cone calorimeter combustion and gasification studies of polymer layered silicate nanocomposites, Chem. Mater., 2002, 14, 881-887.

34 S. Duquesne, M. L. Bras, S. Bourbigot, R. Delobel, G. Camnio, B. Bling, C. Lindsay, T. Roels and H. Vezin, Mechanism of fire retardancy of polyurethanes using ammonium polyphosphate, J. Appl. Polym. Sci., 2001, 82, 3262-3274.

35 D. Yi, R. Yang and C. A. Wilkie, Full scale nancomposites: clay in fire retardant and polymer, Polym. Degrad. Stab., 2014, 105, 31-41.

36 Z. Navratilova, P. Wojtowicz, L. Vaculikova and V. Sugarkova, Sorption of alkylammonium cations on montmorillonite, Acta Geodyn. Geomater., 2007, 4(3), 59-65.

37 M. Trautz, Das gesetz der reaktionsgeschwindigkeit und der gleichgewichte in gasen. Bestätigung der additivität von $\mathrm{Cv}$ $3 / 2 R$. Neue bestimmung der integrationskonstanten und der moleküldurchmesser, Z. Anorg. Allg. Chem., 1916, 96(1), 1-28. 